\title{
Recursos Educacionais Abertos (REA): modelos para localização e adaptação
}

\author{
Tel Amiel 1 \\ Michael Orey ${ }^{2}$ \\ Richard West ${ }^{3}$
}

\section{RESUMO}

Neste artigo apresentamos questões relativas à localização e à adaptação de recursos educacionais digitais. Começamos com uma discussão sobre objetos de aprendizagem (OA) e recursos educacionais abertos (REA). Apresentamos três estratégias que podem auxiliar designers, professores e usuários a refletir sobre a possibilidade de reúso, localização e adaptação cultural de recursos educacionais digitais.

\section{PALAVRAS-CHAVE}

Diversidade cultural; Recursos educacionais abertos; Objetos de aprendizagem; Educação aberta; Design instrucional

\section{Open Educational Resources (OER): models for adaptation and localization}

\begin{abstract}
In this article we present concerns regarding the localization of digital educational resources. We begin with a discussion regarding learning objects $(L O)$ and open educational resources $(O E R)$. Finally we present three strategies that can help designers, teachers, and users to think about the reuse, localization, and cultural repurposing of digital educational resources.

\section{KEYWORDS}

Cultural diversity; Open educational resources; Learning objects; Open education; Instructional design
\end{abstract}

\footnotetext{
${ }^{1}$ NIED/UNICAMP - Brasil.

${ }^{2}$ University of Georgia - Estados Unidos.

${ }^{3}$ Utah State University - Estados Unidos.
} 


\section{INTRODUÇÃO}

Um grande número de repositórios e bibliotecas digitais foi criado, na tentativa de fazer com que recursos educacionais digitais sejam acessíveis a professores e alunos. Esses repositórios têm como objetivo permitir e facilitar acesso a uma variedade de recursos a qualquer pessoa ao redor do mundo. Mas conteúdos educacionais criados em diferentes localidades e diferentes línguas precisam ser adaptados para satisfazer às necessidades de cada localidade. Providenciar o tipo de educação que ensina sobre e para pessoas de diferentes costumes, crenças, valores é uma tarefa essencial da educação (TRINDADE; SANTOS, 1999). Não é possível aceitar a tese de que recursos educacionais, como livros didáticos e recursos multimídia, sejam culturalmente "neutros" ou que possam ser "higienizados" dos seus elementos culturais - remover a cultura de um recurso educacional é impossível (LADSON-BILLINGS, 2004). O design de recursos educacionais que possam acomodar diferentes contextos culturais é um trabalho complexo, porém viável. Ao contrário das previsões mais otimistas, não podemos depender do desenvolvimento de somente alguns recursos de qualidade excepcional que atendam uma grande quantidade de aprendizes do mundo (DOWNES, 2001). Ao mesmo tempo, reconhece-se que recursos educacionais de qualidade excepcional devem ser valorizados e merecem destaque.

Neste artigo, discutimos a questão de localização e adaptação de recursos dentro do movimento para Recursos Educacionais Abertos (REA; Open Educacional Resources). Em um artigo prévio (AMIEL; SQUIRES; OREY, 2009), apresentamos razões e estratégias para que questões culturais sejam elencadas no processo de design de objetos de aprendizagem. Neste trabalho expandimos o trabalho anterior, focando em algumas diferenças entre objetos de aprendizagem e recursos educacionais abertos (REA). Apresentamos as três estratégias e discutimos suas implicações para o processo de design de recursos educacionais abertos. 


\section{OBJETOS DE APRENDIZAGEM E RECURSOS EDUCACIONAIS ABERTOS}

Usamos o termo "objeto de aprendizagem" neste artigo, fazendo referência ao que já se tornou um conceito relativamente conhecido (mesmo que não estável) na área da educação. A definição de Hay e Knaack (2007, p. 6, tradução nossa) talvez seja a mais apropriada dentro do contexto brasileiro, partindo de uma perspectiva pedagógica: “...ferramentas interativas baseadas na web que apoiam o aprendizado de conceitos específicos incrementando, ampliando, ou guiando o processo cognitivo dos aprendizes". O conceito de objeto de aprendizagem tornou-se engessado e confuso, em parte pela enormidade de padrões, sistemas e projetos que tentam definir e direcionar o conceito (WILEY, 2007b). Preferimos utilizar o termo REA, que engloba o conceito de objeto de aprendizagem enfatizando o conceito de abertura. Isso inclui direitos de uso, reúso, revisão, remix e redistribuição (WILEY, 2007b; [s.d.(b)]), bem como facilidades técnicas de adaptação. Utilizamos a seguinte definição de REA: “...a provisão de recursos educacionais fazendo uso de ferramentas tecnológicas, para consulta, uso e adaptação por uma comunidade de usuários com propósitos não-comerciais." (Organização das Nações Unidas para a Educação, a Ciência e a Cultura - UNESCO, 2002, apud WILEY, 2007a, tradução nossa). Por vezes, neste artigo, mantemos o termo "objeto de aprendizagem" para proporcionar maior clareza com relação aos estudos citados.

O conceito de um objeto de aprendizagem é de um recurso reutilizável em diferentes contextos, para diferentes usuários. Wiley (2000) apresenta a complexidade da reutilização, partindo do conceito de granularidade. Definir o nível de granularidade é chave, quando pensamos sobre a reutilização de um recurso dentro de um novo contexto. É muito mais difícil reutilizar um objeto contendo múltiplos itens (imagens, texto, áudio - uma simulação, por exemplo) do que um objeto composto somente de uma imagem. A questão de reúso está muito mais ligada a operações intercontextuais, ou seja, à habilidade de reutilizar um recurso dentro de diferentes contextos. Quanto mais "contexto" há dentro de um recurso, maior a dificuldade de fazer a sua localização (MALCOLM, 2005).

A tradução para o inglês de um objeto criado em português precisaria somente, em princípio, que a informação textual seja apresentada em outra língua. A opção de 


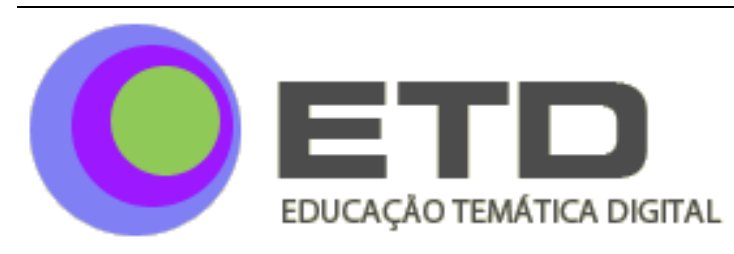

ARTIGO

selecionar a linguagem final poderia ser feita pelo usuário final, o criador, ou por um sistema, de maneira dinâmica. Um exemplo desse tipo de localização é o de sites que permitem colocar e selecionar legendas sobre vídeos (veja, por exemplo, o portal $\operatorname{DotSub}^{4}$ ou o projeto Universal Subtitles ${ }^{5}$ ). Isto é especialmente importante em projetos colaborativos multinacionais, em que os usuários finais podem ter diferentes línguas maternas (como no caso do projeto RIVED $^{6}$ e do portal Europeana ${ }^{7}$ ). A questão maior relativa à adaptação a culturas e nacionalidades é comumente chamada de localização e faz parte do repertório de designers de software e manuais para eles. Essa mesma preocupação emerge com relação à localização de recursos educacionais (DUNN; MARINETTI, 2004). Como nos alerta o trabalho de Nunes e Gaible (2002, p. 112, tradução nossa), a:

...classificação e preparo de multimídia para reúso em diferentes contextos nacionais e internacionais é importante em um mundo globalizado, pressionado pelo excesso de informação, alto custo de desenvolvimento, e complexidade na administração de informação e conhecimento.

O potencial para localização existe, mas devemos pensar nos benefícios e nos méritos pedagógicos da localização de recursos. Como qualquer recurso educacional, o uso de objetos de aprendizagem depende de elementos contextuais endógenos ao recurso. A questão do contexto, na perspectiva do design, refere-se primariamente à flexibilidade do material educacional.

Por princípio, o objeto de aprendizagem foi imaginado como um recurso flexível, oferecendo oportunidades para que seja conectado a outros objetos, correspondendo a algum objetivo de aprendizagem. Já os REAs devem ir além: precisam ser pensados como recursos que podem ser recombinados, mas também reutilizados em contextos diferentes e modificados por outros usuários. O reúso dos recursos em diferentes contextos implica na sua modificação e localização, porém há pouca discussão quanto a como esse processo pode efetivamente ocorrer (WILEY, 2007a; [s.d.(a)]; GUNN et al., 2005). Mesmo que essas oportunidades existam, elas não são de caráter trivial - em grande parte cabe ao designer do recurso promover e fomentar possibilidades de adaptação deste.

\footnotetext{
${ }^{4}<$ http://dotsub.com/>.

$5<$ http://universalsubtitles.org/>.

$6<$ http://rived.mec.gov.br/>.

$7<$ http://www.europeana.com/portal/>.
} 


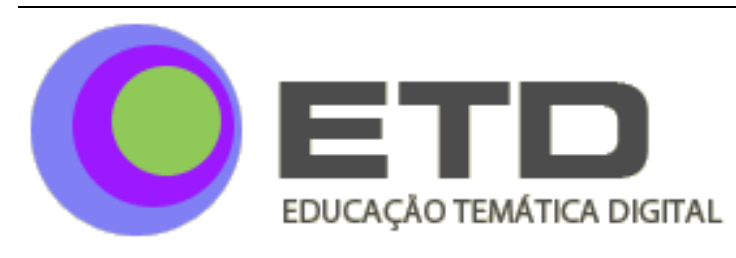

ARTIGO

O debate referente à localização propõe ao menos duas posições, as quais assumem que a questão do contexto merece atenção no processo de design. De um lado, a localização auxilia o aluno a identificar o contexto, minimizando o impacto de elementos não intencionais e teoricamente não referentes aos objetivos educacionais. Por outro lado, a localização dos recursos pode eliminar uma diversidade de contextos e elementos que poderiam agregar ao conteúdo a ser trabalhado:

...é de certa maneira condescendente assumir que aprendizes adultos só podem operar dentro das limitações contextuais de sua própria região geográfica ou cultura étnica. Aí está o paradoxo do movimento para localização: conhecimento padronizado e globalmente utilizável não é realmente global, porque foi localizado. (HENNING et al., 2004)

Há, portanto, a possibilidade de tratar o aluno com pedantismo, como se elementos do design pudessem interferir com os outros elementos focados nos objetivos de aprendizado. A capacidade de discernimento pode variar com a idade do aprendiz e com sua experiência prévia (por exemplo, contato extenso com outros grupos culturais).

A criação ou a localização de um recurso pode ser pensada pela perspectiva de "saliências culturais", uma terminologia derivada do conceito de affordances (GIBSON, 1977). Usamos o termo "saliências culturais" no sentido de elevar os elementos não propositais de um recurso educacional à categoria de uso e análise. Designers instrucionais usam o termo affordance com relação ao "aspecto do design de um objeto que sugere como o objeto deve ser usado" (MCGRENERE; HO, 2000; tradução nossa). Affordances podem ser reais ou legítimas, intuídas; ou podem estar ancoradas na história, na cultura e na experiência do usuário.

Convenções ou vivências culturais são definidas pelo aprendizado coletivo histórico de um grupo. Por exemplo,

o fato que um gráfico no lado direito da tela é uma "barra de rolagem" e que devese posicionar o cursor sobre o mesmo, apertar o botão do mouse, e "arrastar" para baixo para ver objetos localizados abaixo da porção visível é cultural, uma convenção aprendida. Uma convenção é uma restrição cultural, que evolve ao decorrer do tempo e requer uma comunidade de prática. São adotadas lentamente, e quando adotadas, são lentas em partir (NORMAN, 1999). 


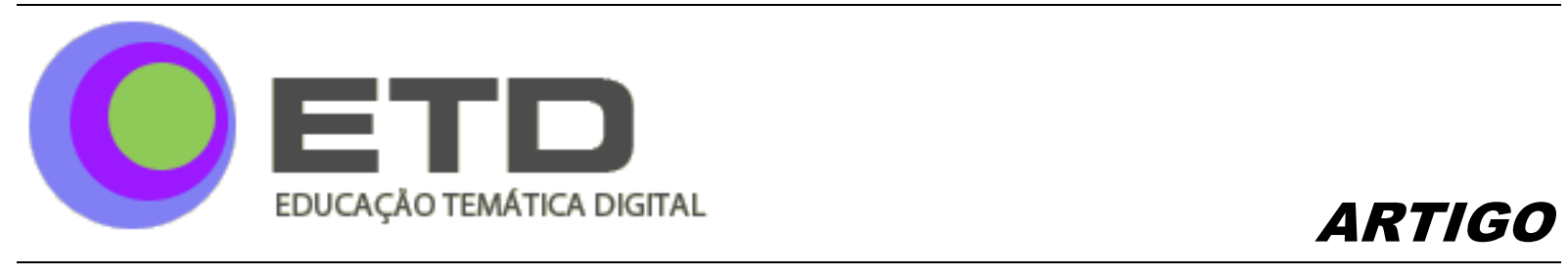

Cada cultura tem restrições em suas convenções aprendidas e compartilhadas pelo grupo. Essas convenções são filtros pelos quais os membros de um grupo veem e respondem ao mundo. Neste artigo, utilizamos a questão de affordances e saliências para fazer referência a possibilidades técnicas (o que é possível com relação a software) bem como a possibilidades de design (no sentido pedagógico/instrucional).

\section{TRÊS MODELOS PARA ADAPTAÇÃO}

A localização de recursos assume, portanto, que há um interesse por parte do usuário, do criador ou do mediador pelo seu reúso. Esse interesse pode ser focado especificamente em salientar a questão cultural ou, simplesmente, permitir a maior abertura possível na sua reutilização. Essa abertura pode gerar benefícios que vão além da questão estritamente cultural. Analisamos o processo de criação de recursos digitais educacionais de acordo com nove quesitos pertinentes ao processo de design (Tabela 1).

Apresentamos o modelo tradicional de design instrucional na categoria Recursos Educacionais (RE), onde os elementos culturais têm dependência no designer (individual ou grupo). Seguimos apresentando três variantes alternativas que têm como objetivo salientar os elementos culturais dos recursos educacionais abertos. Chamamos a primeira alternativa de RESC (Recursos Educacionais com Saliências Culturais), que expande o conceito de RE ao explicitar os elementos culturais e oferecer suporte e explanações (por exemplo: guia para o professor ou aprendiz). As outras duas alternativas contemplam adaptação. A primeira, chamamos de n-Cultura. Neste caso, se os designers sabem que o recurso poderá ser utilizado em diferentes contextos, trazem ao grupo de desenvolvimento pessoas com a necessária diversidade. A última estratégia é REAC (Recursos Educacional com Adaptações Culturais). Este é um recurso educacional altamente flexível, que pode ser adaptado por múltiplos atores em contextos diferentes. Explanamos as quatro categorias a seguir.

No design de um RE, ignora-se o contexto cultural ou faz-se uso de fatores contextuais relevantes a um dado grupo de aprendizes (como é feito em um processo de análise do usuário final). Quando disponibilizado on-line, alguém pode fazer uso desse mesmo recurso em contextos não imaginados pelo designer. Temos, então, um dilema: por 


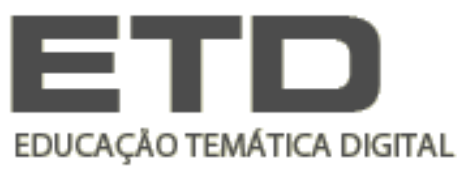

ARTIGO

um lado, os aprendizes não devem ser tão "rígidos" a ponto de negligenciar um "bom" recurso por falta de afinidade cultural. Afinal, esses elementos podem ser educativos, mesmo que para além dos objetivos principais do recurso. Por outro lado, dada a importância de contexto no aprendizado, oportunidades educacionais podem ser perdidas e o conceito de "bom" pode variar em diferentes situações. No caso mais extremo, o aprendiz pode chegar ao recurso, mas não utilizá-lo por barreiras intransponíveis, como seu formato de apresentação ou a língua. Podemos citar o caso comum de um vídeo de uma palestra acadêmica, que, para tornar-se acessível a diferentes grupos tem como requisito básico a colocação de legendas ou tradução. Partindo desta análise, podemos concluir que a maioria dos recursos digitais tradicionalmente definidos como "objetos educacionais" podem ser classificados como RE. São recursos que ignoram ou não priorizam o contexto cultural. Podem facilitar a combinação com outros recursos, mas são de difícil modificação (técnica) por qualquer um que não seja o autor original do recurso digital.

Como qualquer material instrucional, recursos pré-compilados como REs são imbuídos de uma perspectiva cultural. As mensagens implícitas e os contextos inerentes aos recursos educacionais raramente são vistos como um elemento de ensino. Um RESC difere de um RE por incluir um guia ou estratégias instrucionais que se beneficiam do contexto cultural. Baseia-se na seguinte pergunta: "que oportunidades culturais/contextuais de ensino e aprendizagem este recurso pode oferecer?” A resposta é uma análise do recurso e uma busca local por essas oportunidades. Isso significa que um RESC é uma combinação de um recurso comum (RE) e uma série de materiais que ajudam o aprendiz ou instrutor a elaborar sobre o contexto intrínseco ao recurso. 
TABELA 1

Modelos para adaptação e localização de recursos educacionais

\begin{tabular}{|c|c|c|c|c|}
\hline & $\mathbf{R E}$ & RESC & n-Cultura & REAC \\
\hline Contexto $^{8}$ & $\begin{array}{l}\text { Evita a inclusão de } \\
\text { elementos } \\
\text { contextuais, enfoque } \\
\text { em contexto } \\
\text { "genérico" ou grupo } \\
\text { específico. }\end{array}$ & $\begin{array}{l}\text { Criar estratégias } \\
\text { para a integração de } \\
\text { contexto durante o } \\
\text { seu uso. }\end{array}$ & $\begin{array}{l}\text { Criar contextos } \\
\text { alternativos para } \\
\text { reúso como parte do } \\
\text { recurso em si. }\end{array}$ & $\begin{array}{l}\text { Criar para um ou } \\
\text { múltiplos contextos, } \\
\text { mas encorajar } \\
\text { adaptação. }\end{array}$ \\
\hline $\begin{array}{l}\text { Contexto: } \\
\text { Reúso } 9\end{array}$ & Intracontextual & Intercontextual & Intercontextual & Intercontextual \\
\hline $\begin{array}{l}\text { Contexto: } \\
\text { Controle }\end{array}$ & Nenhum prévio & $\begin{array}{l}\text { Durante o uso, } \\
\text { adicional ao uso do } \\
\text { recurso em si }\end{array}$ & $\begin{array}{l}\text { Designer, na análise } \\
\text { de usuários e } \\
\text { desenvolvimento }\end{array}$ & $\begin{array}{l}\text { Usuário final, } \\
\text { adaptação do recurso }\end{array}$ \\
\hline $\begin{array}{l}\text { Abertura: } \\
\text { Facilidade } \\
\text { técnica }\end{array}$ & Fechado, reúso & Fechado, reúso & Fechado, reúso & Aberto, adaptação \\
\hline Localização & $\begin{array}{l}\text { Não apoiado } \\
\text { explicitamente }\end{array}$ & $\begin{array}{l}\text { Limitado, material } \\
\text { extra de apoio }\end{array}$ & $\begin{array}{l}\text { Limitado pelas } \\
\text { opções de "usuário } \\
\text { final" em design }\end{array}$ & $\begin{array}{l}\text { Facilitado por } \\
\text { independência dos } \\
\text { elementos ou } \\
\text { elementos } \\
\text { customizáveis }\end{array}$ \\
\hline $\begin{array}{l}\text { Período de } \\
\text { localização }\end{array}$ & $\begin{array}{l}\text { Design e } \\
\text { desenvolvimento }\end{array}$ & $\begin{array}{l}\text { Design e } \\
\text { desenvolvimento }\end{array}$ & $\begin{array}{l}\text { Design e } \\
\text { desenvolvimento }\end{array}$ & Implementação \\
\hline $\begin{array}{l}\text { Papel do } \\
\text { designer }\end{array}$ & $\begin{array}{l}\text { Tradicional, com } \\
\text { análise de usuário }\end{array}$ & $\begin{array}{l}\text { Exige competência } \\
\text { (multi)cultural ou } \\
\text { assessoria. }\end{array}$ & $\begin{array}{l}\text { Exige grupo: } \\
\text { assessoria, usuários } \\
\text { ou experts. }\end{array}$ & $\begin{array}{l}\text { Exige competência } \\
\text { (multi)cultural. }\end{array}$ \\
\hline $\begin{array}{l}\text { Saliências } \\
\text { culturais }\end{array}$ & $\begin{array}{l}\text { Depende do } \\
\text { educador }\end{array}$ & $\begin{array}{l}\text { Facilitado pelos } \\
\text { materiais } \\
\text { suplementares }\end{array}$ & $\begin{array}{l}\text { Múltiplas } \\
\text { representações } \\
\text { disponíveis através } \\
\text { do recurso em si }\end{array}$ & $\begin{array}{l}\text { Possibilita a } \\
\text { customização local } \\
\text { baseada no contexto e } \\
\text { no uso. }\end{array}$ \\
\hline $\begin{array}{l}\text { Barreiras } \\
\text { instrucionais }\end{array}$ & $\begin{array}{l}\text { Contexto é implícito } \\
\text { e dependente da } \\
\text { perspectiva do } \\
\text { designer }\end{array}$ & $\begin{array}{l}\text { Contexto é } \\
\text { explícito, porém os } \\
\text { elementos } \\
\text { suplementares } \\
\text { podem ser } \\
\text { ignorados ou pouco } \\
\text { úteis. }\end{array}$ & $\begin{array}{l}\text { O grupo pode não } \\
\text { ser representativo. } \\
\text { Tempo de } \\
\text { coordenação. Os } \\
\text { contextos } \\
\text { imaginados podem } \\
\text { não satisfazer os } \\
\text { usuários finais. }\end{array}$ & $\begin{array}{l}\text { Planejamento e } \\
\text { desenvolvimento } \\
\text { mais intensivo }\end{array}$ \\
\hline Exemplos & $\begin{array}{l}\text { Simulações ou } \\
\text { vídeos disponíveis } \\
\text { on-line; livros em } \\
\text { formatos fechados } \\
\text { para download }\end{array}$ & $\begin{array}{l}\text { Repositórios e } \\
\text { recursos com guias } \\
\text { para uso; webquests } \\
\text { com páginas para } \\
\text { instrutores }\end{array}$ & $\begin{array}{l}\text { Avaliação } \\
\text { formativa; design } \\
\text { participativo; } \\
\text { recursos adaptáveis } \\
\text { via template ou } \\
\text { escolhas do usuário }\end{array}$ & $\begin{array}{l}\text { Espaços abertos } \\
\text { colaborativos como } \\
\text { Wikis; sistemas web } \\
\text { que permitam remix } \\
\text { dos recursos } \\
\text { disponíveis. }\end{array}$ \\
\hline
\end{tabular}

\footnotetext{
${ }^{8}$ Veja PARRISH, 2004.

${ }^{9}$ Veja WILEY, 2000.

${ }^{10}$ Refere-se a etapas do tradicional modelo de design instrucional ADDIE: análise, design, desenvolvimento, implementação e avaliação (veja, por exemplo, Thomas, Mitchell e Joseph, 2002).
} 


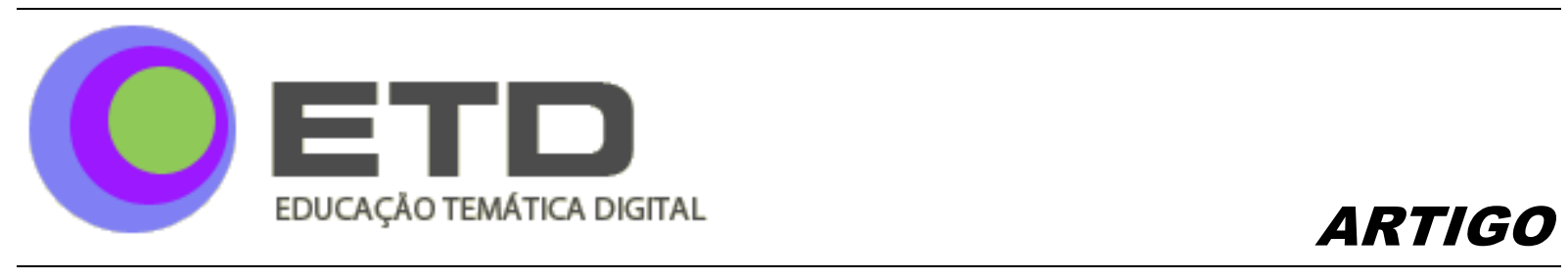

Como exemplo, podemos citar o webquest $^{11}$. O modelo tradicional de um webquest solicita a inclusão de um "guia para o professor", que deve expor questões contextuais, recursos necessários e explicitar as intenções do criador do webquest ao seu usuário (um outro professor, por exemplo). Os recursos do projeto RIVED são tecnicamente fechados, porém aproximam-se do conceito de RESC quando incluem "guias para uso" direcionados aos professores.

Os RESC são descritivos de grande parte dos recursos disponíveis em portais com foco explicitamente educacional, mesmo que muitas vezes as descrições para uso não enfoquem a questão cultural, mas sim definições de procedimento e contexto. São recursos que permanecem tecnicamente fechados, porém promovem a utilização em contextos diferentes - utilização intercontextual. Exige do usuário um interesse em rever as considerações do designer e adaptar o recurso às condições locais.

Existe, portanto, a possibilidade de capitalizar os elementos inerentes a um recurso educacional qualquer e proporcionar a oportunidade para reflexão sobre questões culturais. Ao mesmo tempo, temos que considerar a importância da localização como parte do processo de design. O objetivo do modelo n-Cultura é trazer ao design as experiências e o conhecimento cultural dos designers e de usuários diversos, por vezes pertencentes aos grupos para os quais os recursos são destinados (HENDERSON, 1996). O “n”, em n-Cultura representa simbolicamente o número de "culturas" representadas em um grupo de design. Em uma circunstância simplificada, poderíamos equacionar cultura com nacionalidade. Neste caso, se o recurso será desenvolvido para usuários de três países, é esperado que ao menos um representante ou expert de cada grupo faça parte da equipe. O importante é incluir o conhecimento de uma diversidade representativa que melhor informe o design do recurso para os públicos-alvo.

Cabem aqui também modelos de design participativo, em que o expert pode ser um usuário final potencial. Muitos projetos têm incorporado a participação de alunos e professores no design de software e recursos educacionais com sucesso (MELO et al., 2002;

\footnotetext{
${ }^{11}<$ http://webquest.org/>.
} 


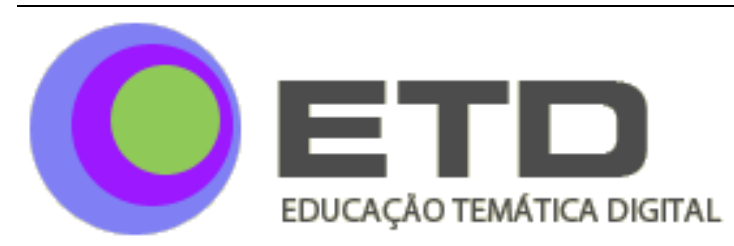

ARTIGO

NUNES; GAIBLE, 2002). O resultado final pode ser somente um recurso estático formado pela influência do grupo diversificado. Idealmente, porém, seria um recurso contendo conteúdo direcionado a diferentes públicos, ou seja, um recurso que contenha opções de configuração e apresentação a serem selecionadas pelo instrutor ou usuário final. Nesse sentido, um recurso n-Cultura é tecnicamente fechado, mas tem maior facilidade de transitar em diferentes contextos.

Para promover a contextualização, o controle sobre o design de um recurso deve aproximar-se do usuário final; este é o objetivo do modelo REAC. Gunn, Woodgate e O'Grady (2005) apontam a falta da participação e do sentimento de propriedade no design como um fator principal na falta de adoção de objetos de aprendizagem. Como apontamos anteriormente, os recursos educacionais abertos têm como princípio a possibilidade de reúso e adaptação. Porém, o design tradicional não contempla que este recurso possa ser modificado ou alterado pelo usuário final. Partindo do conceito do design participativo, Fischer et al. (2004, p. 35, tradução nossa) caracterizam essa possibilidade como "metadesign":

\begin{abstract}
Meta-design caracteriza objetivos, técnicas, e processos para se criar novas mídias e ambientes permitindo os "donos dos problemas" (quer dizer, os usuários finais) a agir como designers. Um objetivo fundamental do meta-design é o de criar ambientes sócio-técnicos que fortaleçam usuários a engajar ativamente no desenvolvimento contínuo de sistemas ao invés de se restringirem ao simples uso dos sistemas.
\end{abstract}

No caso de recursos complexos, com menor granularidade, como simulações e outros recursos multimídia, são disponibilizados em sua versão compilada (por exemplo, uma simulação desenvolvida em Adobe Flash). Se, após a criação do recurso, modificações fossem contempladas, somente o designer teria a possibilidade de fazê-las, recompilando e distribuindo o recurso. O fortalecimento do usuário final facilita o círculo virtuoso que permite a criação, a modificação e a distribuição de recursos educacionais abertos. O modelo de Shneiderman (2002) em quatro simples passos serve, de maneira simples, para delinear esse ciclo: o usuário busca recursos digitais disponíveis (1); relaciona esses recursos a outros existentes ou criados (2); cria, portanto, um novo recurso (3) que deve ser disponibilizando para outros usuários (4). Para que este ciclo aconteça com facilidade, é necessário que o processo de adaptação seja facilitado. 


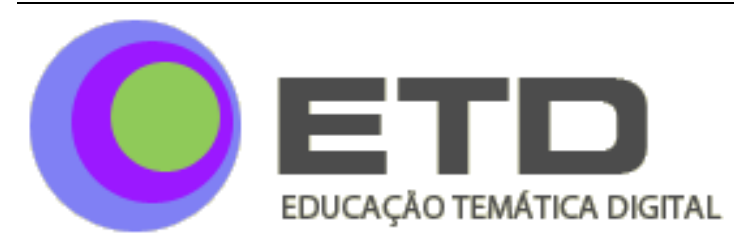

ARTIGO

Já existem possibilidades técnicas simples que auxiliam esse processo - basta que o designer tenha em mente esse ciclo virtuoso e facilite a adaptação. Podemos citar o portal Connexions $^{12}$, que tem o processo de remix como parte essencial de sua estrutura, bem como exemplos mais simples, como o de um desenho em quadrinhos chamado "Prisioneira da lei: sagas do domínio público", criado pela Duke University. O quadrinho, originalmente em inglês, está disponível on-line ${ }^{13}$ com uma licença Creative Commons ${ }^{14}$. Este primeiro passo faz com que o recurso seja aberto, no sentido de proporcionar a oportunidade legal (com suas devidas restrições) para que o usuário final modifique o material e crie recursos derivados. Mas o que é exemplificado por esse projeto é sua abertura no sentido de flexibilidade técnica. O quadrinho está disponível em inúmeros formatos. Primeiro, em formatos compatíveis com inúmeros dispositivos (Adobe PDF e Flash), porém inflexíveis no quesito adaptação - não é fácil "desmontar" um arquivo Flash para adaptação. Segundo, disponibiliza páginas individuais e texto de forma avulsa para adaptação por usuários finais. Com atenção a questões técnicas, os autores encorajam a tradução e a adaptação do recurso ${ }^{15}$. São, portanto, dois fatores essenciais no quesito abertura: a abertura legal com licenças flexíveis e, segundo, abertura no sentido técnico, facilitando o processo de adaptação do recurso digital ${ }^{16}$.

\section{CONCLUSÃO}

Há ainda, um enorme gargalo para a criação, o uso e a adaptação de recursos educacionais. $\mathrm{O}$ acesso aos dispositivos — como o computador — que permitam acesso e uso é somente o primeiro passo. Mesmo que tenhamos dois bilhões de usuários on-line, a grande maioria não tem fácil acesso a ferramentas para adaptação e reúso (NÚMERO DE USUÁRIOS DE INTERNET PASSARÁ DE 2 BILHÕES NESTE ANO, AFIRMA ONU, 2010). Existem ainda importantes questões relacionadas à fluência tecnológica dos usuários e dos designers para que haja adaptação e reúso. Abordamos algumas dessas questões em

\footnotetext{
$12<$ http://cnx.org/>.

$13<$ http://www.law.duke.edu/cspd/comics/>.

${ }^{14}$ Especificamente, a licença é “Atribuição-Uso não-comercial-Compartilhamento pela mesma licença". Veja mais em 〈http://creativecommons.org/licenses/by-nc-sa/2.5/br/>.

${ }^{15}$ Pertinente a nossa discussão, a seguinte afirmação encoraja os usuários: "Artistas, advogados, professores, e alunos - customizem o quadrinho para a sua região. Você pode traduzir o quadrinho por completo, ou qualquer parte dele (algumas páginas, uma imagem), dependendo do seu propósito.” (tradução nossa, veja $<$ http://www.law.duke.edu/cspd/comics//>).

${ }^{16}$ Para uma discussão sobre licenças e direitos autorais no Brasil, veja Rossini, 2010.
} 
outros trabalhos (AMIEL, 2006; AMIEL, 2008; AMIEL; MCCLENDON; OREY, 2007). Devemos promover melhores condições de acesso ao mundo digital em escala global ${ }^{17}$ e, paralelamente, levantar as questões necessárias para que os que têm (e terão) acesso possam efetivamente fazer uso e produção de recursos educacionais digitais.

Apesar da crescente facilidade para criação e reúso de recursos digitais, devemos reconhecer que todos carregam consigo elementos culturais, propositalmente ou não. Ignorar esses elementos pode diminuir consideravelmente o número de usuários de um recurso. Pode ser visto também como neocolonialismo ${ }^{18}$, na medida em que usuários de países mais pobres ou com menor distribuição de renda se tornam meros consumidores ou tradutores de conteúdos (CERI, 2007). Os elementos culturais estão sempre presentes e oferecem barreiras muitas vezes intransponíveis ao usuário final. Reconhecer a existência dessas barreiras é um importante passo no caminho para uma educação mais aberta e inclusiva. A questão é definir não se, mas como devemos tratar a diversidade cultural no design de recursos educacionais abertos.

\section{REFERÊNCIAS}

AMIEL, T. Mistaking computers for technology: technology literacy and the digital divide. AACE Journal, v. 14, n. 3, 2006. Disponível em: 〈http://www.editlib.org/>. Acesso em: 15 jan. 2011.

Interculturalidad y TICs: una relación cíclica. Aplicaciones educativas y nuevos lenguajes de las TIC, p. 193-206, 2008.

AMIEL, T.; MCCLENDON, J.; OREY, M. A model for international collaborative development work in schools. Education Media International, v. 44, n. 2, p. 167-179, 2007.

AMIEL, T.; SQUIRES, J.; OREY, M. Four strategies for designing instruction for diverse cultures. Educational Technology, v. 49, n. 6, p. 28-34, 2009.

\footnotetext{
${ }^{17}$ Veja, por exemplo, a iniciativa da UNESCO de promover acesso à banda larga em todo o mundo. Disponível em: 〈http://www.broadbandcommission.org/>.

${ }_{18}$ Iniciativas recentes, como a da Universidade Virtual da África, vão na contramão do "neo-colonialismo" digital (http://oer.avu.org).
} 
CERI. Giving knowledge for free: the emergence of open educational resources. Paris: OECD, 2007

DOWNES, S. Learning objects: resources for distance education worldwide. International Review of Research in Open and Distance Learning, jul. 2001. Disponível em: < http://www.irrodl.org/index.php/irrodl/article/view/32/378>. Acesso em: 1 fev. 2011.

DUNN, P.; MARINETTI, A. Cultural adaptation: necessity for global eLearning. LiNEZine, 2004.

FISCHER, G. et al. Meta-design: a manifesto for end-user development. Communications of the ACM, v. 47, n. 9, p. 33-37, 2004.

GIBSON, J. J. The theory of affordances. In: SHAW, R. e BRANSFORD, J. (Ed.). Perceiving, acting, and knowing. Hillsdale, NJ: Erlbaum, 1977.

GUNN, C.; WOODGATE, S.; O'GRADY, W. Repurposing learning objects: A sustainable alternative? ALT-J: Research in learning technology, v. 13, n. 3, p. 189-200, 2005.

HAY, R. H.; KNAACK, L. Evaluating the learning in learning objects. Open Learning: The Journal of Open and Distance Education, v. 22, n. 1, p. 5-28, 2007.

HENDERSON, L. Instructional design of interactive multimedia: a cultural critique. Educational Technology Research and Development, v. 44, n. 4, p. 85-104, 1996.

HENNING, E. et al. 'Adapting' cultures for localisation of elearning: multicultural overcompensation or access to global learning pathways? In: WORLD CONFERENCE ON EDUCATIONAL MULTIMEDIA, HYPERMEDIA AND TELECOMMUNICATIONS, 2004, Lugano. Proceedings... Norfolk: Association for the Advancement of Education, 2004. p.5431-5437.

LADSON-BILLINGS, G. New directions in multicultural education: Complexities, boundaries, and critical race theory. In: JAMES A. BANKS, C. A. M. B. (Ed.). Handbook of research on multicultural education. 2.nd. San Francisco, CA: John Wiley \& Sons, 2004. p.50-65. ISBN 0-7879-5915-4.

MALCOLM, M. The exercise of the object: Issues in resource reusability and reuse. British Journal of Educational Technology, v. 36, n. 1, p. 33-41, 2005.

MCGRENERE, J.; HO, W. Affordances: clarifying an evolving concept. Montreal: Graphics Interface 2000, 2000.

MELO, A. M. et al. Trazendo a criança para o processo de design: uma abordagem participativa à criação de portais. In: Congresso da Sociedade Brasileira de Computação, 22, 2002, Florianópolis. Anais... Florianópolis: SBC, 2002. p. 375-382. 


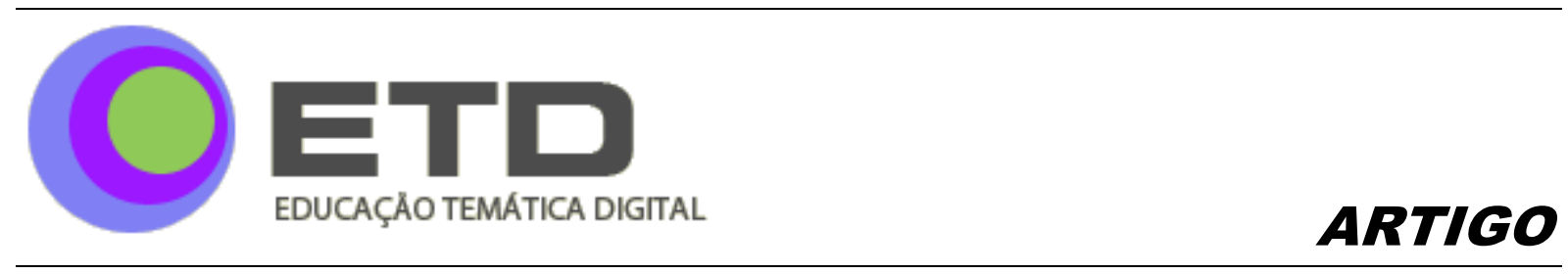

NORMAN, D. Affordance, conventions, and design. Interactions, p. 48-43, maio 1999.

NUNES, C.; GAIBLE, E. Development of multimedia materials. In: HADDAD, W. D. e DRAXLER, A. (Ed.). Technologies for education: potentials, parameters, and prospects. Paris: UNESCO, 2002. p.94-117.

PARRISH, P. E. The trouble with learning objects. Educational Technology Research and Development, v. 52, n. 1, p. 49-67, 2004.

ROSSINI, C. Green-Paper: the state and challenges of OER in Brazil: from readers to writers? Harvard University. Boston: February, p.75. 2010. Disponível em: $\leq$ http://rea.net.br/materiais-de-referencia/>. Acesso em: 1 de Fevereiro, 2011.

SHNEIDERMAN, B. Leonardo's laptop. Cambridge, MA: MIT Press, 2002.

THOMAS, M.; MITCHELL, M.; JOSEPH, R. The third dimension of ADDIE: A cultural embrace. Techtrends, v. 46, n. 2, p. 40-45, 2002.

TRINDADE, A. L. D.; SANTOS, R. D. (Ed.). Multiculturalismo: mil e uma faces da escola. Rio de Janeiro, RJ: DP\&A. 1999.

WILEY, D. Defining the "open" in open content. s.d. Disponível em: < http://opencontent.org/definition/ >. [s.d.(b)] Acesso em: 10 jan. 2011.

Learning objects and the new CAI: so what do I do with a learning object.

[s.d.(a)]. Disponível em 〈http://opencontent.org/docs/instruct-arch.pdf >. Acesso em: 20 jan. 2011.

On the sustainability of open educational resource initiatives in higher education. [s.1.]: OECD, 2007a

Openess, localization, and the future of learning objects. 2007b. Disponível em: < http://opencontent.org/presentations/bcnet07/ >. Acesso em: 5 jan. 2011.

. (Ed.). The instructional use of learning objects: on-line version. 2000. Disponível em < http://www.reusability.org/read/ >. Acesso em: 20 jan. 2011. 